\title{
GOVERNANCCA CORPORATIVA (GC) NAS INSTITUIÇÔES DE ENSINO SUPERIOR: UM MAPEAMENTO SISTEMÁTICO DA PRODUÇÃO CIENTÍFICA NACIONAL
}

Data de submissão: 02/06/2014 Aceite: 17/09/2016

Degson Ferreira ${ }^{1}$

Tara Keshar Baidya²

Marta Corrêa Dalbem ${ }^{3}$

\section{RESUMO}

O objetivo deste trabalho foi identificar e discutir o perfil da produção científica nacional e a evolução do tema Governança Corporativa (GC) em Instituições de Ensino Superior (IESs) nos artigos publicados no SPELL, no Google Acadêmico e nas revistas nacionais com Qualis entre A2 e B5, no período 2005-2013, bem como delinear e caracterizar os principais temas e abordagens metodológicas que predominam nessa produção. Para tanto, realizou-se um estudo bibliométrico com 51 artigos, utilizando-se de abordagem quantitativa. Os resultados mostram que as pesquisas descritivas, qualitativas e estudos de caso são predominantes nos artigos e aqueles com dois ou três autores ocorrem com maior frequência. Mostram ainda que os dois autores mais prolíficos têm 4 publicações cada um, e que a área apresentou um crescimento em 2005-2009, mas tornou-se errática em 2010-2013 em relação ao número de artigos publicados e se caracteriza por estar baseada em temas emergentes e diversos como percepção dos stakeholders, responsabilidade social corporativa (RSC), estrutura de propriedade e de controle, GC em IESs familiares, disclosure e accountability, GC versus desempenho e governança de TI.

Palavras-Chave: Governança Corporativa; Instituição de Ensino Superior; Análise Bibliométrica.

1 Possui graduação em Administração com habilitação em Gestão de Sistemas de Informação pela Faculdade de Ciências e Educação de Rubiataba FACER, mestrado em Administração pela Universidade Federal de Rondônia - UNIR e doutorado em Administração pela Universidade do Grande Rio UNIGRANRIO. Araguaina-TO. Brasil. E-mail: degsonfer@gmail.com

2 Possui graduação em Química pela Tribhuban University, T.U., Nepal, mestrado em Engenharia Química pela University of London, UL, Inglaterra, mestrado em Administração de Empresas pela Florida State Unversity, F.S.U., Estados Unidos e doutorado em Administração de Empresas pela University of California, Berkeley, U.C. (BERKELEY), Estados Unidos. Rio de Janeiro-R. Brasil. E-mail: tarabaidya@yahoo.com.br

3 Possui graduação em Engenharia Civil pela Universidade Federal do Rio de Janeiro, UFR, mestrado em Administração pela UFR e doutorado em Administração de Empresas pela Pontifícia Universidade Católica do Rio de Janeiro, PUC-Rio. E-mail: martadalbem@hotmail.com 


\section{INTRODUÇÃO}

Um dos principais resultados da globalização e das transformações pelas quais passaram as economias de todo o mundo nas últimas décadas foi o crescimento das empresas e uma tendência à diluição do controle acionário, passando-se a exigir também maior atenção aos demais atores afetados pelas empresas. Neste processo, tem sido necessário o desenvolvimento de um sistema de preservação de direitos, de organização das relações, da estrutura de poder e de valores segundo os quais as sociedades e as companhias são dirigidas, controladas e administradas, sistema esse denominado Governança Corporativa (GC), conforme a definição do Cadbury Committee (1992).

Assim, não é de se estranhar que nos últimos anos vários autores (WILLIAMSON, 1996; CLAESSENS e FAN, 1996; SHLEIFER e VISHNY, 1997; BABIC, 2003; MONKS e MINOW, 2004) e instituições (OCDE, 2004; IBGC, 2010) têm surgido para analisar a diversidade de questões relacionadas à governança corporativa, propondo soluções.

Para a Organização para a Cooperação e Desenvolvimento Econômico (OECD, 2004), a governança corporativa envolve um conjunto de relações entre a gestão de uma empresa, seu conselho de administração, seus acionistas e outras partes interessadas. Ela também fornece a estrutura por meio da qual os objetivos da empresa são estabelecidos, e define os meios de se atingir esses objetivos e os instrumentos para se monitorar o desempenho (OECD, 2004).

A discussão conceitual e teórica sobre governança corporativa iniciou-se nos anos 1930, com a publicação do texto clássico de Berle e Means (1932) ao mostrarem que as empresas americanas constituíam um sistema disperso de propriedade, o que originava conflitos entre administradores e acionistas decorrentes de situações de oportunismo gerencial. Porém, de acordo com autores como Muritiba et. al. (2010) e Araújo, Mendes e Lustosa (2012), somente em 1980 a governança corporativa tornou-se um tema central para as empresas.

Em termos acadêmicos, somente a partir de 1980 é que tal abordagem passou a ser estudada e veiculada com maior freqüência em periódicos e eventos internacionais, mostrando que a GC é um tema relativamente recente e também bastante voltado para empresas com fins lucrativos e para os setores industrial e de serviços. No entanto, instituições de ensino também enfrentam questões importantes de governança, e já há uma literatura envolvendo essa interface entre GC e Instituições de Ensino Superior (IESs) que merece ser mapeada e analisada, visando deflagrar futuros trabalhos correlatos.

Embora existam, na literatura nacional, estudos envolvendo a interface entre GC e IESs, não há trabalhos nacionais nas áreas de Administração, Ciências Contábeis, Economia e Turismo que tratam desta interface sob o ponto de vista bibliométrico, o que fundamenta o interesse em desenvolver esta pesquisa e ratifica, assim, a sua originalidade e ineditismo.

Desta forma, espera-se nesta pesquisa avançar no assunto, apresentando um panorama da produção científica nacional dos últimos 9 anos dos artigos e trabalhos que se encontram na base dados da biblioteca eletrônica de periódicos científicos (Scientific Periodicals Electronic Library - SPELL), bem como no Google Acadêmico e nas revistas nacionais classificadas com Qualis entre A2 e B5. Os periódi$\cos \mathrm{A} 1$ das áreas de Administração, Ciências Contábeis e Turismo não foram pesquisados por excederem o escopo e recorte deste estudo, o qual incidiu somente sobre a produção científica nacional.

Este trabalho procura respostas para a seguinte questão de pesquisa: qual é o perfil da produção científica nacional e a evolução do tema GC em IESs nos artigos e trabalhos publicados no SPELL, no Google Acadêmico e nas revistas nacionais das áreas de Administração, Ciências Contábeis e Turismo com Qualis entre A2 e B5, no período compreendido entre os anos de 2005 e 2013?

Em busca de respostas para esta pergunta, este trabalho teve como objetivo identificar e discutir o perfil da produção científica e a evolução deste tema em IESs nos artigos e trabalhos 
publicados no SPELL, no Google Acadêmico e nas revistas nacionais das áreas de Administração, Ciências Contábeis e Turismo com Qualis entre A2 e B5, no período compreendido entre os anos de 2005 e 2013. Adicionalmente, o trabalho busca delinear e caracterizar os temas mais discutidos, as abordagens metodológicas predominantes, os principais autores e redes de pesquisa.

\section{GOVERNANÇA CORPORATIVA}

\subsection{Evolução da Governança Corporativa}

O desenvolvimento da Governança Corporativa (GC) tem raízes firmes e fortes razões para se disseminar. Organizações multilaterais, como as Nações Unidas e a OCDE, veem as boas práticas de GC como pilares da arquitetura econômica global e um dos instrumentos do desenvolvimento em suas três dimensões: a econômica, a social e a ambiental (ROSSETTI e ANDRADE, 2012).

Nessa mesma linha de raciocínio, Polo (2007) resume os canais pelos quais a governança corporativa afeta o crescimento e desenvolvimento econômico: aumento de acesso ao financiamento externo por parte das empresas, menor custo de capital associado a uma maior valorização da empresa, melhor desempenho operacional por meio de uma melhor alocação de recursos e melhor gestão, redução do risco de crises financeiras e melhores relações com todas as partes interessadas (stakeholders).

Ocorre que nos últimos 30 anos aconteceram várias razões simultâneas para o despertar e para os avanços da GC: a onda de privatizações, as reformas dos fundos de pensão, o crescimento da poupança privada, a desregulamentação e a integração dos mercados de capitais. Somando a estes fatos, Polo (2007) destaca que escândalos e falências envolvendo corporações na Europa e nos Estados Unidos podem ser considerados os responsáveis pelo interesse renovado na realização de pesquisas na área de governança corporativa.

Assim, a GC desenvolveu-se principalmente como consequência dos oportunismos proporcionados pelo afastamento dos proprietários passivos. Segundo Rossetti e Andrade (2012), entre os trabaIhos pioneiros, evidenciando os conflitos entre proprietários e gestores e a ascensão da tecnoestrutura das organizações como novo fator de poder, destacam-se os de Berle e Means (1932) e os de Galbraith (1967). O trabalho de Berle e Means (1932) examinou o desalinhamento entre proprietários passivos e não proprietários usufrutuários; o de Galbraith (1976) destacou como os gestores, controladores da complexa tecnoestrutura organizada, tornaram-se o fator mais importante de sustentação do mundo corporativo.

De acordo com Rossetti e Andrade (2012), a GC surgiu para cuidar desses conflitos e de outros desalinhamentos nas companhias. Das reações de ativistas por boas práticas de GC resultaram a criação de mecanismos legais e de marcos regulatórios protecionistas dos direitos e interesses dos acionistas, bem como mudanças internas nas organizações, com ênfase na constituição de conselhos eficazes e guardiões.

Para Shleifer e Vishny (1997), a GC lida com as maneiras pelas quais os fornecedores de recursos financeiros das corporações tentam assegurar o retorno financeiro dos seus investimentos realizados. Segundo o Instituto Brasileiro de Governança Corporativa (IBGC, 2010), a governança corporativa representa o sistema pelo qual as empresas são dirigidas, monitoradas e incentivadas, contemplando as relações entre os acionistas/cotistas, o conselho de administração, a diretoria, o conselho fiscal e a auditoria independente. As boas práticas de governança corporativa têm por objetivo preservar e aumentar o valor da empresa, facilitar seu acesso ao capital e contribuir para a continuidade dos negócios (IBGC, 2010).

Resulta oportuno acrescentar que não há evidências de que a implantação de governança corporativa produza maiores resultados tangíveis tais como lucros, valorização do capital, etc. Ainda assim, a GC é essencial por contemplar aspectos legais e éticos. 
Numa abordagem mais ampla, Fontes Filho e Picolin (2008) esclarecem que boas práticas de governança reduzem a assimetria de informações entre investidores e gestores ou empreendedores, equilibram os direitos entre acionistas majoritários e minoritários e, por conseguinte, fortalecem o mercado de capitais como mecanismo de financiamento às empresas. Esse fortalecimento amplia o nível de liquidez do mercado, reduzindo o prêmio de risco e tornando menos onerosa a captação de recursos pela empresa. Esse sistema de equilíbrio nas relações e segurança legal, ao facilitar o fluxo de recursos às empresas, exerce papel importante para a promoção do desenvolvimento econômico e financeiro dos países (FONTES FILHO e PICOLIN, 2008).

Cabe observar, de acordo com Silveira (2010), que um sistema de governança somente será eficiente se for capaz de combinar mecanismos internos (como a ação do conselho de administração; o sistema de remuneração dos executivos; a concentração acionária; e a atuação dos investidores institucionais) e externos (como a proteção legal dos investidores; a possibilidade de aquisição hostil; o grau de competição no mercado; a fiscalização dos agentes de mercado; a estrutura de capital) com o objetivo de assegurar decisões que caminhem para o melhor interesse de longo prazo dos acionistas.

\subsection{Governança Corporativa nas Instituições de Ensino Superior}

A governança, de modo amplo, trata da aquisição e distribuição de poder na sociedade, enquanto a governança corporativa diz respeito à maneira pela qual as organizações são administradas de uma maneira geral (MATIAS-PEREIRA, 2010).

Assim, a GC ocupa-se da forma de administração e controle de uma instituição qualquer, seja empresarial ou não, com ou sem fins lucrativos ou filantrópicas, controladas por capitais públicos ou privados, e qualquer que seja a forma adotada, societária, associativa, comunitária, fundacional ou cooperativa (SANTOS, 2008).

Segundo o IBGC (2010), em seu código das melhores práticas de GC, os princípios e práticas da boa GC aplicam-se a qualquer tipo de organização, independente do porte, natureza jurídica ou tipo de controle. O referido código utiliza a palavra organização a fim de tornar o documento o mais abrangente possível e adaptável a outros tipos de organizações, como, por exemplo, as do Terceiro Setor, cooperativas, estatais, fundações e órgãos governamentais, entre outras.

Desta forma, pretende-se ampliar o estudo nesta área e estender a teoria de GC para fora do ambiente privativo de companhias abertas. Para tanto, parte-se do pressuposto de que qualquer organização possui uma estrutura de governança, um conjunto de princípios e procedimentos e controles que disciplina as relações entre os diversos agentes envolvidos ou que participam de sua atividade.

De acordo com a matriz teórica analisada, constata-se que existem, ainda que de forma incipiente, estudos envolvendo o assunto GC e IES. Diante disso, a seguir são abordados alguns trabalhos sobre a temática GC e IES e seus aspectos mais relevantes.

Os autores Duarte, Khalil e Quelhas (2008) tiveram como objetivo verificar se as instituições de ensino pesquisadas conheciam e praticavam o modelo de gestão com base em governança, relacionando as melhores práticas de governança disseminadas pelo IBGC com as utilizadas pelas instituições de ensino. Dentre as principais conclusões, encontram-se que as organizações estudadas possuem processos e práticas informais de GC, ou seja, não possuem a consciência de que praticam esses processos e consequentemente não valorizam a importância deste novo modelo de gestão.

Santos (2008) fez um estudo que teve como objetivo analisar as relações entre a estrutura de propriedade e controle e as práticas de GC com o desempenho em uma IES. Concluiu que há relações entre a governança corporativa na IES e seu desempenho financeiro. Por outro 
lado, não foi possível verificar, com tanta nitidez, uma relação direta entre a GC e o desempenho acadêmico na instituição pesquisada.

Mainardes, Deschamps e Tontini (2009) tiveram como objetivo entender as percepções dos stakeholders (diretor, coordenadores, professores, alunos, ex-alunos e empregadores) sobre a qualidade de uma IES, sobretudo dos cursos de administração, utilizando as oito dimensões para a qualidade do modelo de Shanahan e Gerber (2004) e as onze do Sistema Nacional de Avaliação da Educação Superior (SINAES). Por meio de entrevistas com 33 stakeholders, seguindo a metodologia fenomenográfica, concluíram que as dimensões de qualidade propostas por Shanahan e Gerber (2004) e as dimensões avaliadas pelo SINAES estavam presentes no estudo.

Outro trabalho interessante foi o dos autores Silva Júnior, Muniz e Martins (2009), que teve como objetivo descrever e analisar a configuração da GC e os impactos na gestão universitária de uma IES familiar identificada como Universidade Familiar Carioca (UFC). Os resultados indicaram que a GC da UFC caracterizou-se pela dissociação entre mantenedora e mantida, num ambiente político dinâmico e complexo na gestão universitária em que múltiplos interesses se articulam entre os mais diversos atores sociais (proprietários, gestores e familiares). Constataram-se a separação dos papéis de empreendedor (exercido pelo proprietário familiar) e de gestor (exercido pelos gestores da mantenedora e da mantida) e a profissionalização da gestão.

Em seu estudo, Galvão, Corrêa e Alves (2011) propuseram o desenvolvimento de um modelo alternativo de avaliação de desempenho global para as IESs com base no SINAES e considerando outros modelos de avaliação de desempenho organizacional como, por exemplo, o Modelo de Excelência da Gestão (MEG), da Fundação Nacional da Qualidade (FNQ), o Prêmio Americano de Qualidade Malcolm Baldrige (BNQP), o European Foundation for Quality Management (EFQM), o Sigma Sustainbility e o Balanced Scorecard (BSC). Após a realização do estudo e comparação dos modelos de avaliação, foi elaborado o modelo de avaliação de desempenho global e concluíram que o sistema de avaliação fundamentado no SINAES não é o único modelo válido e que o sistema proposto contribui para melhorar a gestão e o desempenho organizacional das IESs, criando valor superior nos seus serviços oferecidos, além de contribuir também para o desenvolvimento e aprofundamento de novos estudos e modelos.

Já os autores Nogueira, Garcia e Ramos (2012) objetivaram investigar, junto a uma IES pública, em que aspectos a sua gestão aproxima-se dos elementos componentes da GC e suas relações com a responsabilidade social corporativa (RSC) da instituição. Concluíram que a instituição estudada está de acordo com o referencial utilizado sobre GC e com os princípios e práticas deste tema. Em relação à RSC, identificaram que a IES estudada não apresenta uma política institucional formalizada, voltada para a comunidade.

Esses trabalhos comprovaram que a GC e IES são um assunto emergente e que justifica maior esforço de pesquisa no Brasil. Entretanto, é válido destacar que ele vem sendo estudado com uma consistência maior nos últimos anos, razão pela qual se constata a necessidade de mapear seu crescimento e as eventuais lacunas, de modo a fomentar novas pesquisas científicas sobre esta temática.

\section{PROCEDIMENTOS METODOLÓGICOS}

Trata-se de um estudo de análise bibliométrica, que se destina a identificar e analisar o perfil da produção científica nacional e a evolução do tema em questão, utilizando-se da abordagem quantitativa por meio de estatística descritiva. Este estudo é uma pesquisa descritiva (GIL, 2002; CERVO e BERVIAN, 1996; LEITE, 2004), pois visa transcrever, descrever, interpretar e explicar o resultado do estudo obtido na análise bibliométrica do perfil da produção científica e a evolução do tema no Brasil. 
Para Leite Filho (2006), indicadores de performance bibliométrica são importantes para analisar e avaliar a pesquisa acadêmica, nortear rumos e estratégias de futuras pesquisas. $O$ planejamento de uma pesquisa de análise bibliométrica, segundo Cooper e Lindsay (1998), envolve quatro etapas importantes adicionais à etapa de formulação do problema de pesquisa, a saber: a escolha da literatura analisada, a avaliação dos dados coletados, a análise e interpretação das informações e a apresentação dos resultados.

Assim, com relação ao período de publicação, os trabalhos em estudo foram delimitados entre os anos de 2005 e 2013, correspondendo aos últimos nove anos. Uma das bases de dados utilizada foi o Scientific Periodicals Electronic Library (SPELL), um sistema de indexação, pesquisa e disponibilização da produção científica, vinculado à Associação Nacional de Pós-Graduação e Pesquisa em Administração (ANPAD). O SPELL teve seu início em 2012 e concentra a produção científica das áreas de Administração, Contabilidade, Economia, Engenharia e Turismo. Durante a pesquisa, o banco de dados do SPELL contava com 10.932 trabalhos publicados, 1.634 .675 downloads e 4.315 .080 acessos (SPELL, 2013). Usaram-se os seguintes filtros para a busca: (i) palavraschave - governança e instituição de ensino superior, ou governança corporativa e programa de pós-graduação, ou governança e ensino superior; (ii) período de publicação - entre janeiro de 2005 e novembro de 2013; (iii) Tipo de documento - artigo; (iv) área de conhecimento - administração, contabilidade e economia; e (v) idioma - espanhol, francês, inglês e português.

Adotando esses parâmetros para a seleção dos artigos, foi possível identificar um total de 86 artigos publicados no SPELL que abordavam o tema GC ou Ensino Superior. Posteriormente à seleção dos artigos, foi efetuada uma leitura dos títulos, resumos, palavras-chave, metodologias e conclusões, buscando identificar aqueles trabalhos que tratavam da interface entre GC e IES. Após adotar esses procedimentos, restaram apenas 27 artigos para análise.

Outra base de dados consultada foi a do Google Acadêmico (Google Scholar, em inglês), lançado em novembro de 2004, passando a oferecer buscas em língua portuguesa em 10 de janeiro de 2006. Ele é uma ferramenta de pesquisa do Google que disponibiliza várias disciplinas e fontes em um só lugar e permite pesquisar artigos revisados por especialistas (peer-rewiewed), teses, livros, resumos e artigos de editoras acadêmicas, organizações profissionais, bibliotecas de pré-publicações, universidades e outras entidades acadêmicas (GOOGLE ACADÊMICO, 2013).

Os critérios e mecanismos utilizados no Google Acadêmico para a busca de trabalhos foram: (i) encontrar artigos com todas as palavras - governança ou governança corporativa; (ii) com no mínimo uma das palavras - instituição de ensino superior ou ensino superior; (iii) onde minhas palavras ocorrem - no título do artigo; (iv) período de publicação - entre 2005 e 2013; e (v) pesquisar na Web.

Com o uso desses parâmetros para a seleção dos trabalhos, foi possível identificar um total de 27 artigos publicados no Google Acadêmico que abordavam o tema GC ou IES. Posteriormente à seleção dos trabalhos, foi efetuada uma leitura dos títulos, resumos, palavras-chave, metodologias e conclusões, buscando identificar aqueles que tratavam da interface entre GC e IES. Utilizando estes procedimentos, restaram apenas 19 trabalhos para a análise.

Diante dessa pequena quantidade de trabalhos encontrados, uma nova consulta também foi efetuada no banco de dados de 119 revistas nacionais das áreas de Administração, Ciências Contábeis e Turismo, classificadas com Qualis entre A2 e B5. Os mecanismos de busca utilizados foram os seguintes: (i) pesquisar termo - governança, ou governança corporativa, ou ensino superior, ou instituição de ensino superior, ou governança e ensino superior; (ii) data - de 01 janeiro de 2005 até 08 de novembro de 2013.

Com base nesses filtros para a seleção dos artigos e efetuando uma leitura dos títulos, resumos, palavras-chave, metodologias e conclusões, de modo a identificar aqueles que tratavam da interface entre GC e IES, foi possível encontrar um total de 35 artigos publicados nessas 119 revistas. 
Um resumo da estratégia realizada para determinar os termos de busca utilizados para responder a questão de pesquisa pode ser visualizado na Figura 1.

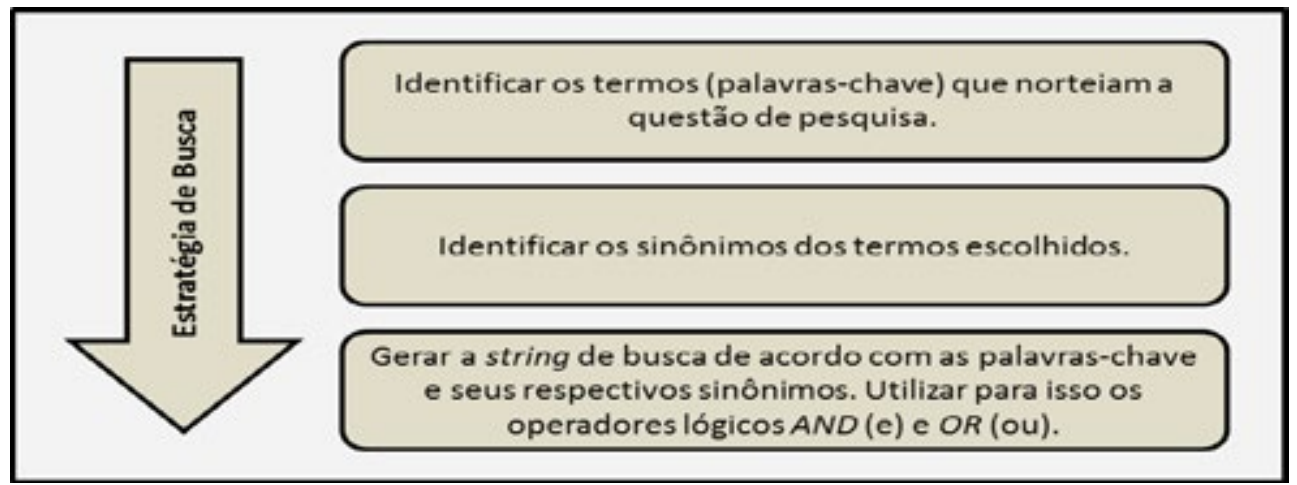

Figura 1 - Resumo da Estratégia para Realização das Buscas

Fonte: elaboração própria

De acordo com os passos descritos na Figura 1 foram estabelecidas as palavras-chave e as suas respectivas strings de busca que foram aplicados para a consulta no SPELL, no Google Acadêmico e nas principais revistas nacionais das áreas de Administração, Ciências Contábeis e Turismo, conforme podem ser visualizadas na síntese da Figura 2.

\begin{tabular}{|c|l|l|}
\hline \multirow{2}{*}{ SPELL } & \multicolumn{1}{|c|}{ Palavras-Chave } & \multicolumn{1}{c|}{ String de Busca } \\
\cline { 2 - 3 } & $\begin{array}{l}\text { Governança e instituição de ensino supe- } \\
\text { rior, ou governança corporativa e progra- } \\
\text { ma de pós-graduação, ou governança e e } \\
\text { ensino superior. }\end{array}$ & $\begin{array}{l}\text { ("governança and instituição de ensino supe- } \\
\text { rior" OR "governança corporativa and programa } \\
\text { de pós-graduação" OR "governança e ensino } \\
\text { superior") }\end{array}$ \\
\hline $\begin{array}{c}\text { Google } \\
\text { Acadêmico }\end{array}$ & $\begin{array}{l}\text { Governança e instituição de ensino superior, } \\
\text { ou governança corporativa e ensino superior. }\end{array}$ & $\begin{array}{l}\text { ("governança and instituição de ensino superior" } \\
\text { ORovernança corporativa and ensino superior") }\end{array}$ \\
\hline $\begin{array}{c}\text { Revistas } \\
\text { Nacionais }\end{array}$ & $\begin{array}{l}\text { Governança, ou governança corporativa, } \\
\text { ou ensino superior, ou instituição de ensino } \\
\text { superior, ou governança e ensino superior. }\end{array}$ & $\begin{array}{l}\text { ("governança" OR "governança corporativa" OR } \\
\text { "gerior" OR "gorior" OR "instituição de ensino su- }\end{array}$ \\
\hline
\end{tabular}

Figura 2 - Síntese das Palavras-Chave e String de Busca

Fonte: elaboração própria

Alguns dos trabalhos e artigos identificados se encontravam em mais de um dos sistemas de pesquisa/bases de dados. Assim, a amostra final totalizou apenas 51 artigos, sendo 35 artigos publicados em periódicos e 16 outros trabalhos disponíveis em meio eletrônico on-line como, por exemplo, aqueles apresentados em colóquios, congressos, encontros, seminários e simpósios, além de dissertações de mestrado e teses de doutorado, conforme pode ser visualizada na Tabela 1.

Tabela 1: Total de Artigos e Trabalhos da Amostra Final

\begin{tabular}{|c|c|c|c|c|c|c|}
\hline \multirow{2}{*}{$\begin{array}{l}\text { Total de Artigos sobre GC } \\
\text { \& IES, Identificados nas } \\
\text { Bases de Dados } \\
\text { Total }(a+b)\end{array}$} & \multicolumn{2}{|c|}{$\begin{array}{l}\text { Quantidade de Artigos } \\
\text { e Trabalhos Duplicados } \\
\text { nas Bases de Dados }\end{array}$} & \multirow[t]{2}{*}{$\begin{array}{l}\text { Sub-Total } \\
\text { (a) }\end{array}$} & \multicolumn{2}{|c|}{$\begin{array}{l}\text { Artigos e Trabalhos que } \\
\text { Compõem a Amostra Final }\end{array}$} & \multirow{2}{*}{$\begin{array}{l}\text { Sub-Total } \\
\text { (b) }\end{array}$} \\
\hline & $\begin{array}{l}\text { Q u a n t. } \\
\text { Artigos }\end{array}$ & $\begin{array}{l}\text { Q u a } \mathrm{n} \mathrm{t} . \\
\text { Trabalhos }\end{array}$ & & Quant. Artigos & 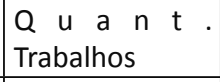 & \\
\hline 81 & 30 & -- & 30 & 35 & 16 & 51 \\
\hline $100 \%$ & $37,04 \%$ & -- & $37,04 \%$ & $43,21 \%$ & $19,75 \%$ & $62,96 \%$ \\
\hline
\end{tabular}

Fonte: elaboração própria 
Os artigos foram lidos e organizados em gráficos e tabelas de estatística descritiva que ajudaram a proceder às análises e às comparações entre as variáveis. A análise de variância (ANOVA) também foi usada para estudar a diferença entre médias de dois ou mais grupos. Os aspectos abordados neste estudo foram: (i) artigos publicados; (ii) número de autores por artigos; (iii) ano de publicação; (iv) principais autores; (v) principais periódicos; (vi) principais temas de base; (vii) tipos de pesquisas; (viii) métodos de pesquisas; (ix) procedimentos metodológicos utilizados; $(\mathrm{x}$ ) instrumentos de coleta e análise dos dados.

\section{RESULTADOS E DISCUSSÃO}

O número de autores que publicam cada artigo evidencia redes e parcerias entre autores. $\mathrm{Na}$ medida em que mais autores publicam em conjunto, percebe-se que a área é investigada por grupos de pesquisa ao invés de autores individuais, um possível indicativo de disseminação do tema. Segundo Subramanyam (1983), a colaboração entre autores vem sendo vista internacionalmente como um dos indicadores de qualidade da pesquisa, principalmente em temas interdisciplinares, como é o caso da GC.

Os dados coletados revelam que os trabalhos e artigos publicados nos periódicos consultados (Figura 3) variam de um a seis autores. Nesta figura, verifica-se que os artigos envolvendo dois, três e quatro autores equivalem a $70,7 \%$ do total analisado, podendo ser um indicativo da existência de grupos de pesquisadores ou redes de pesquisa sobre a temática. Entretanto, artigos com um autor representam $21,6 \%$ do total. Essa informação sugere que os pesquisadores podem estar trabalhando sob um sistema de insulamento e individualidade, com poucas relações de intercâmbio e compartilhamento de experiência e conhecimentos entre si. Pela análise da estatística descritiva, é possível identificar que 3 (moda) é quantidade de autores que ocorre com maior frequência nos artigos publicados, e que eles foram escritos, em média, por 2,59 autores. Porém, o desvio padrão de 1,24 permite inferir que existe uma considerável dispersão da quantidade de autores em relação à sua média.

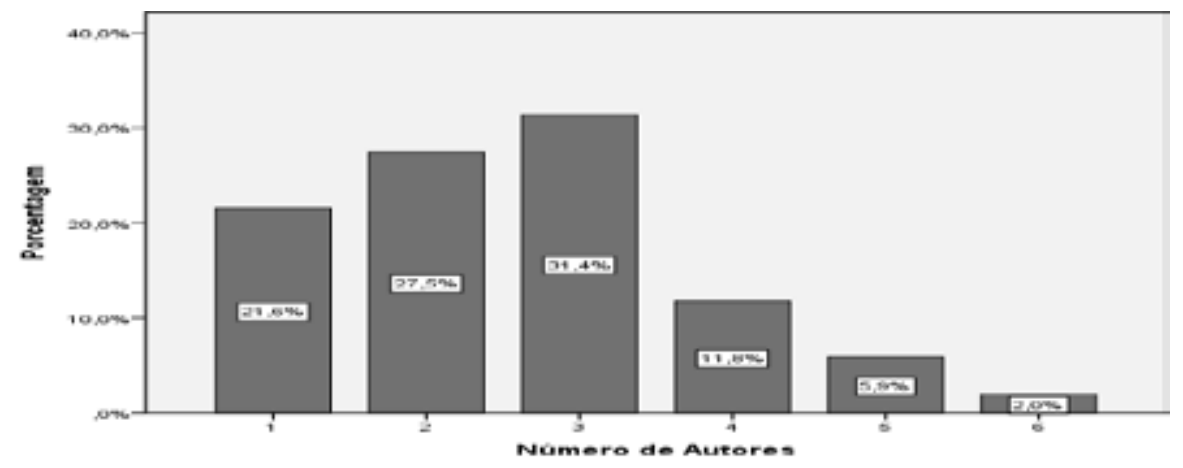

Figura 3 - Percentual de Autores por Artigo Fonte: dados da pesquisa (2013)

Para o desenvolvimento do estudo, delimitaram-se as publicações entre os anos de 2005 e 2013, sendo este último referente aos primeiros dez meses do ano. Verificou-se que houve pouca ocorrência de estudos relacionados ao tema nos anos de 2005 e 2006, isso pode ser em decorrência do surgimento apenas no início daquela década das primeiras iniciativas que marcaram a introdução das boas práticas de GC no Brasil. A distribuição foi crescente a partir do ano de 2007 até 2009, partindo de 5,9\% (2007), passando por 7,8\% (2008), alcançando 15,7\% (2009). Em 2010, houve uma leve queda para 11,8\%, atingindo o patamar máximo observado de $25,5 \%$ no ano de 2012 (Figura 4). Como a pesquisa foi realizada até o dia 08 de novembro de 2013, é 
bem provável que a quantidade de trabalhos que ainda foram produzidos no ano de 2013 não ultrapassou o total produzido no ano de 2012. A produção média, no período analisado, foi de 5,7 artigos e trabalhos publicados. Contudo, os dados estão espalhados por diversos valores, mostrando que há uma alta variação ou dispersão da quantidade produzida e publicada de artigos em torno da média, como pode ser comprovada com a identificação de um desvio padrão de 3,7 .

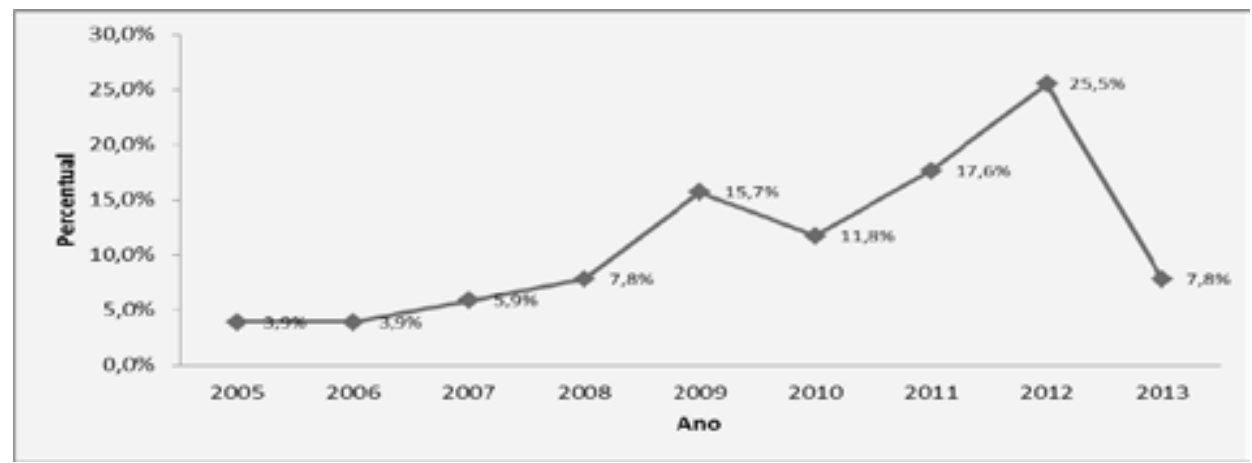

Figura 4 - Evolução dos Artigos por Ano de Publicação Fonte: dados da pesquisa (2013)

Dos 131 autores, aqueles com maior produção no período analisado envolvendo a interface GC em IES são, a saber: Annor da Silva Júnior e Emerson Wagner Mainardes, com 4 publicações cada um; Maria José Carvalho de Souza Domingues e Reynaldo Maia Muniz, com 3 publicações; e Antônio Carlos Giuliani, Eduardo Eugênio Spers, Fábio Vinicius de Macedo Bergamo, Felipe Zambaldi, Mateus Canniatti Ponchio e Priscilla de Oliveira Martins, com 2 publicações cada um. Entretanto, vale ressaltar que o autor Annor da Silva Júnior publicou 3 trabalhos com Reynaldo Maia Muniz, sendo que a autora Priscilla de Oliveira Martins estava presente em dois deles. Cabe observar também que dos 4 trabalhos de Emerson Wagner Mainardes, 3 foram em parceria com a autora Maria José Carvalho de Souza Domingues. A mesma estratégia de parceria ou de redes de pesquisa acontece entre os autores Antônio Carlos Giuliani, Fábio Vinicius de Macedo Bergamo, Felipe Zambaldi e Mateus Canniatti Ponchio na produção de 2 artigos (Figura 5). Os demais autores apareceram na produção de somente um artigo cada um, no período analisado.

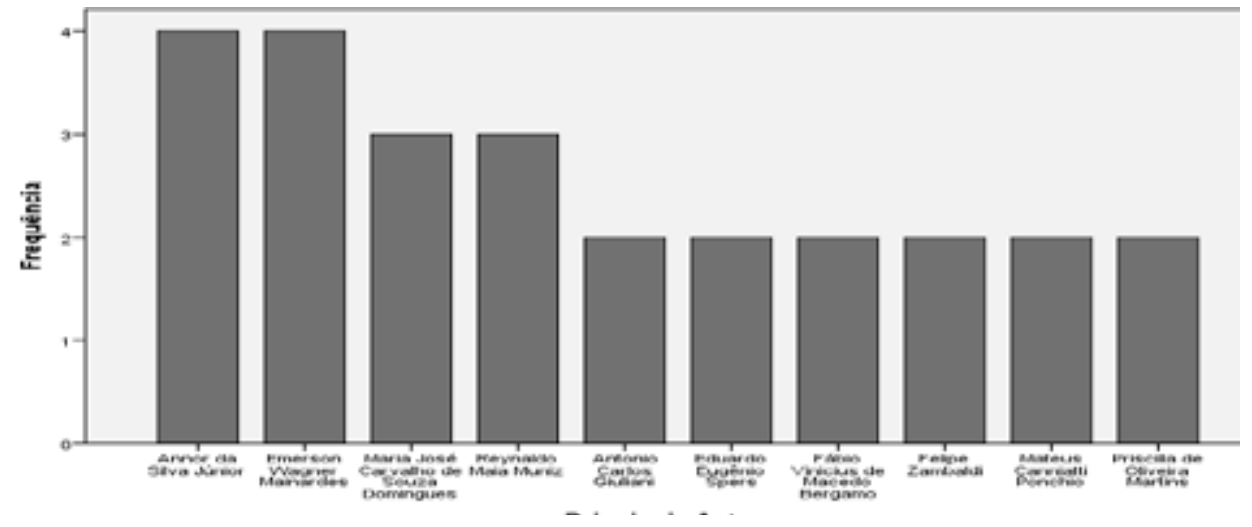

Figura 5 - Autores com Maior Produção na Temática Fonte: dados da pesquisa (2013) 
Os principais assuntos da GC nas IESs discutidos por esses autores envolvem a estrutura de propriedade e controle, empresa familiar, impactos da GC na gestão universitária e para os principais stakeholders de IES, percepção dos stakeholders sobre a gestão da qualidade nas IES e determinantes da satisfação de alunos.

As abordagens metodológicas preferidas pelos autores foram analisadas de forma a que se possa ter uma ideia da predominância de determinados tipos, métodos e procedimentos de pesquisa utilizados pelos pesquisadores do tema ora em estudo. Para realizar esta análise, foram utilizadas as informações fornecidas pelos próprios autores sobre o tipo, o método e os procedimentos de pesquisa que eles seguiram. Não cabe a este estudo julgar eventuais incongruências, já que se tratam de artigos aprovados em revistas ou eventos que possuem procedimentos de revisão (MURITIBA et al. 2010).

Sendo assim, ao analisar a Figura 6, verifica-se que as pesquisas descritivas são predominantes nos estudos de GC nas IES nos periódicos e demais fontes analisadas. Os dados coletados mostram que $43,1 \%$ dos artigos e trabalhos publicados foram descritivos; seguidos por estudos exploratórios, com 41,2\%; e estudos exploratório-descritivos, com 15,7\%, concentrando, assim, os tipos de pesquisa sobre governança corporativa em instituições de ensino superior.

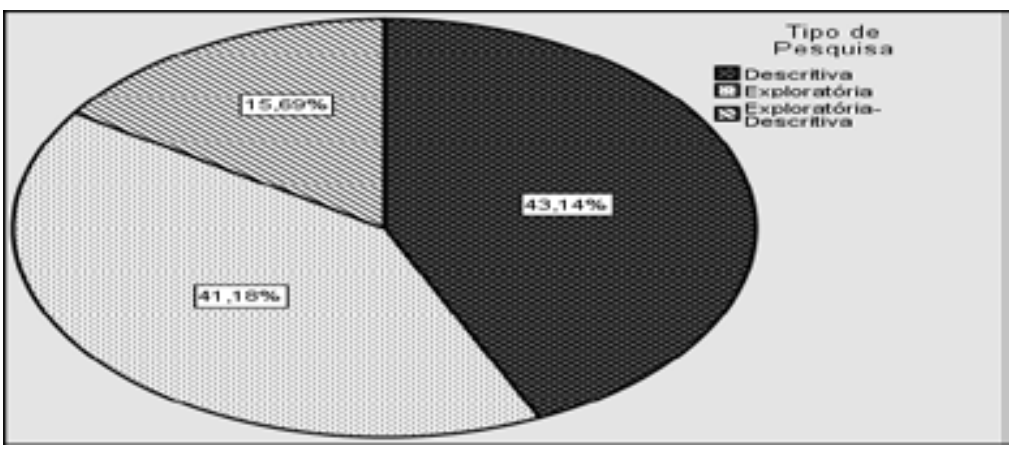

Figura 6 - Tipo de Pesquisa

Fonte: dados da pesquisa (2013)

A análise de variância (ANOVA) é técnica estatística que permite comparar a diferença de médias de três ou mais grupos (FIELD, 2009; MALHOTRA, 2012). Foi verificado por meio da ANOVA se existe diferença no número de autores em relação ao tipo de pesquisa. Percebe-se pela Tabela 2 que os 21 trabalhos exploratórios têm em média 2,19 autores; os 22 trabalhos descritivos têm em média 03 autores; e os 08 trabalhos exploratório-descritivos têm em média 2,5 autores. Embora as médias do número de autores desses tipos de pesquisa sejam levemente diferentes, os intervalos de confiança apresentam grande sobreposição. Assim, qualquer diferença entre as médias pode ser atribuída ao erro amostral. 
Tabela 2: ANOVA do Número de Autores em Relação ao Tipo de Pesquisa

\begin{tabular}{|c|c|c|c|c|c|c|}
\hline & & \multirow{2}{*}{ № de Casos Válidos } & \multirow{2}{*}{ Média } & \multicolumn{3}{|c|}{ Intervalo de confiança de $95 \%$ para média } \\
\hline & & & & Limite inferior & \multicolumn{2}{|c|}{ Limite superior } \\
\hline Exploratória & & 21 & 2,19 & 1,59 & \multicolumn{2}{|c|}{2,79} \\
\hline Descritiva & & 22 & 3,00 & 2,53 & \multicolumn{2}{|c|}{3,47} \\
\hline Exploratória-Descr & & 8 & 2,50 & 1,50 & \multicolumn{2}{|c|}{3,50} \\
\hline Total & & 51 & 2,59 & 2,24 & \multicolumn{2}{|c|}{2,94} \\
\hline \multicolumn{7}{|c|}{ ANOVA } \\
\hline & \multicolumn{2}{|c|}{ Soma dos Quadrados } & $\begin{array}{l}\text { df* } \\
\text { (gl)* }\end{array}$ & Média dos Quadrados & $\mathbf{F}$ & Sig. \\
\hline Entre Grupos & \multirow{2}{*}{\multicolumn{2}{|c|}{$\begin{array}{c}7,115 \\
69,238\end{array}$}} & 2 & 3,557 & \multirow[t]{2}{*}{2,466} & \multirow[t]{2}{*}{0,096} \\
\hline Dentro de Grupos & & & 48 & 1,442 & & \\
\hline Total & \multicolumn{2}{|r|}{76,353} & 50 & & & \\
\hline
\end{tabular}

*df = degree free $(\mathbf{g l}=$ graus de liberdade)

Múltiplas Comparações

Variável dependente: Número de Autores

Tukey HSD

\begin{tabular}{|cc|c|c|}
\hline (I) Tipo de Pesquisa & (J) Tipo de Pesquisa & $\begin{array}{c}\text { Diferença média } \\
\text { (I-J) }\end{array}$ & Sig. \\
\hline Exploratória & Descritiva & $-0,810$ & 0,080 \\
& Exploratória-Descritiva & $-0,310$ & 0,810 \\
\hline Descritiva & Exploratória & 0,810 & 0,080 \\
& Exploratória-Descritiva & 0,500 & 0,575 \\
\hline Exploratória-Descritiva & Exploratória & 0,310 & 0,810 \\
& Descritiva & $-0,500$ & 0,575 \\
\hline
\end{tabular}

Fonte: dados da pesquisa (2013)

Esta tabela mostra que a soma dos quadrados para o teste entre grupos é 7,1 e para o teste dentro dos grupos é 69,24. Desta maneira, a análise mostra que $F(2,48)=2,47, p>0,05$. Essa análise de variância do número de autores em relação ao tipo de pesquisa empregado mostrou que qualquer diferença entre as condições é provável de ter ocorrido apenas por erro de amostragem, considerando que a hipótese nula seja verdadeira. Também mostra que não existe uma diferença estatisticamente significativa entre as médias dos grupos de pesquisas exploratórias e as dos grupos de pesquisas descritivas em relação ao número de autores. Do mesmo modo, também não existem diferenças estatisticamente significativas entre as médias dos grupos de pesquisas exploratórias e as dos de pesquisas exploratório-descritivas, bem como entre as pesquisas descritivas e as exploratório-descritivas.

Para a categoria método de pesquisa, utilizou-se como subcategoria a classificação de Creswell $(2007$, p. 35), a qual indica que as técnicas de pesquisa podem qualitativa, quantitativa e de métodos mistos ou híbridos (qualitativa e quantitativa).

A Figura 7 evidencia a predominância dos estudos qualitativos, representando $58,8 \%$ do total de trabalhos e artigos publicados. Os estudos quantitativos representam $37,3 \%$ dos trabalhos divulgados; e 3,9\% das pesquisas desenvolvidas pelos pesquisadores utilizam o método híbrido ou misto, ou seja, são quali-quantitativas. 


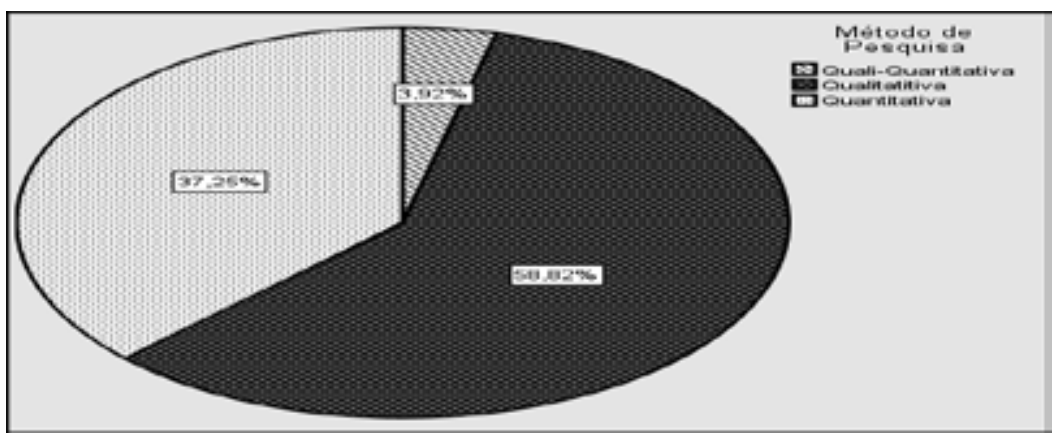

Figura 7 - Método de Pesquisa

Fonte: dados da pesquisa (2013)

Pode-se entender como fator positivo a evolução do número de artigos e trabalhos de natureza qualitativa (ARAGÃO et al., 2010) nos dias de hoje. A predominância de estudos qualitativos pode ser decorrência da grande parte dos trabalhos e artigos pesquisados no período em questão trabalhar a abordagem de Estudo de Caso (Figura 8). Tal afirmação é corroborada também por autores como Walter et al. (2008), ao afirmarem em seu estudo que quase $52 \%$ dos estudos de caso empregam técnicas de análise qualitativa.

Relacionando o tipo de pesquisa com o método utilizado pelos autores, pode-se notar pela tabulação cruzada (Tabela 3 ) que dos $43,1 \%$ dos artigos e trabalhos descritivos publicados, a maioria $(31,4 \%)$ utiliza o método de pesquisa quantitativo; todos os $41,2 \%$ de estudos exploratórios usam o método qualitativo; e dos 15,7\% de estudos exploratório-descritivos, 5,9\% utilizam o método qualitativo e esse mesmo percentual aplica-se também para o método quantitativo, seguidos de $3,9 \%$ que utiliza o método misto.

Tabela 3: Tabulação Cruzada entre Tipo e Método de Pesquisa

\begin{tabular}{|cc|c|c|c|c|}
\hline \multirow{2}{*}{} & & \multicolumn{3}{|c|}{ Método de Pesquisa } & Total \\
& & Qualitativo (\%) & Quantitativo (\%) & Quali-Quantitativo (\%) & (\%) \\
\hline Tipo de & Exploratória & 41,2 & -- & -- & $\mathbf{4 1 , 2}$ \\
Pesquisa & Descritiva & 11,7 & 31,4 & -- & $\mathbf{4 3 , 1}$ \\
& Exploratória-Descritiva & 5,9 & 5,9 & 3,9 & $\mathbf{1 5 , 7}$ \\
\hline & Total (\%) & $\mathbf{5 8 , 8}$ & $\mathbf{3 7 , 3}$ & $\mathbf{3 , 9}$ & $\mathbf{1 0 0}$ \\
\hline
\end{tabular}

Fonte: dados da pesquisa (2013)

O estudo buscou também identificar os procedimentos de pesquisa mais utilizados pelos autores. Estudos de casos práticos foram os predominantes, com 37,3\% dos trabalhos e artigos publicados; seguidos de $29,4 \%$ de multicasos. Constatou-se também uma grande frequência de estudos bibliográficos, com $21,6 \%$, seguidos de $9,8 \%$ que realizaram surveys e de $2 \%$ que fizeram uma pesquisa-ação (Figura 8). 


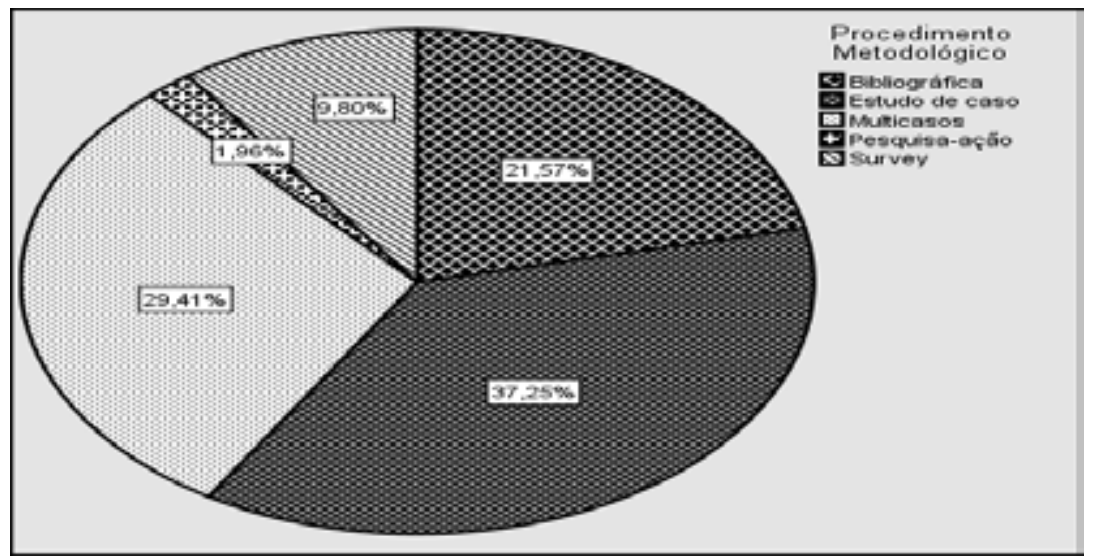

Figura 8 - Procedimento de Pesquisa

Fonte: dados da pesquisa (2013)

Aragão et al. (2010) afirmam que nos últimos anos o estudo de caso tem sido uma abordagem amplamente utilizada nos estudos sociais, principalmente por pesquisadores que realizam investigações de cunho qualitativo, continuando assim, a ser um método de pesquisa marcante para a temática (SERRA et al., 2008).

No que diz respeito aos instrumentos de coleta dos dados utilizados nos trabalhos e artigos pesquisados, a Figura 9 mostra a predominância de questionários estruturados, estando presente em $20(39,2 \%)$ dos 51 trabalhos, tanto naqueles que fizeram estudo de caso quanto naqueles que adotaram estudos multicasos e survey como procedimento metodológico. A consulta em livros, artigos científicos e sites especializados apareceu em $9(17,6 \%)$ trabalhos, que são puramente bibliográficos. A entrevista semiestruturada, se considerada de forma isolada, aparece em $14(27,4 \%)$ trabalhos; se considerada em conjunto com a análise de conteúdo, aparece em $7(13,7 \%)$ trabalhos, e com a análise de discurso, aparece em 4 (7,8\%) trabalhos. Como técnica de análise dos dados, a análise de conteúdo e de discurso se consideradas de forma separada evidenciam-se em $13(25,5 \%)$ trabalhos, o que, conseqüentemente, reitera a utilização de abordagens qualitativas pelos autores, conforme destacado na Figura 7.

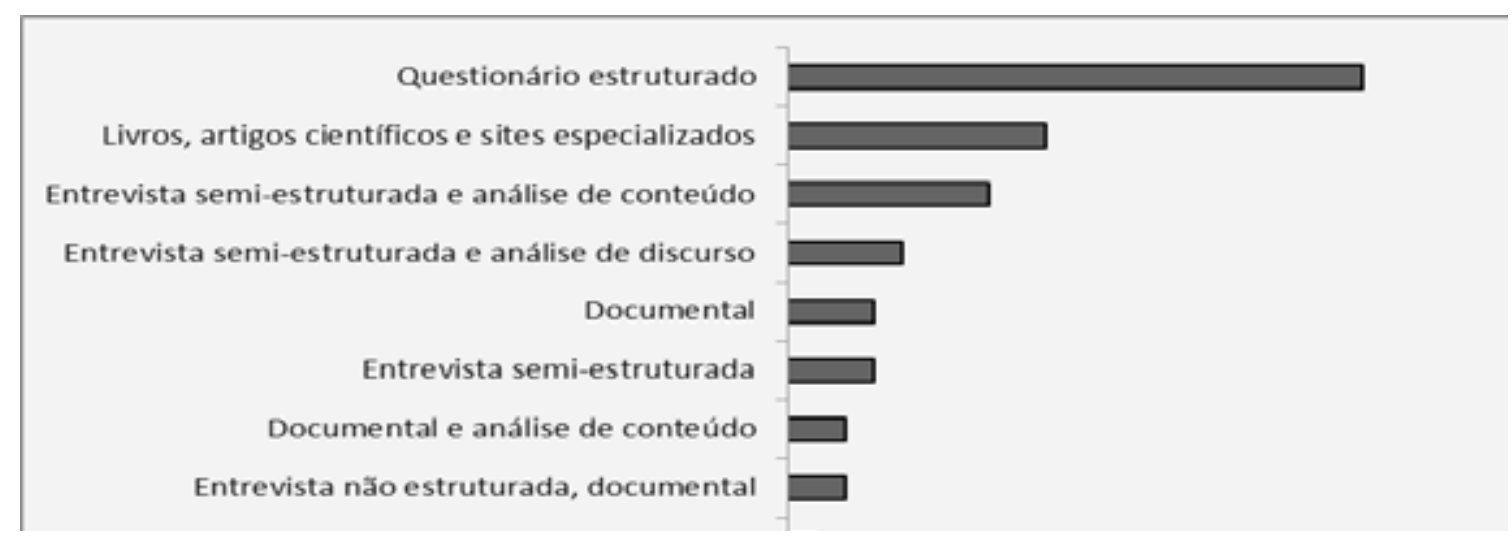

Figura 9 - Instrumento de Coleta e Análise de Dados

Fonte: dados da pesquisa (2013)

Os resultados das Figuras 7, 8 e 9 também sugerem mais uma ratificação ou uma busca 
de sinais da presença de práticas de governança nas IES e não uma busca por melhorias dos modelos em si, talvez porque boas práticas de GC são uma temática emergente - iniciada em 1999 com publicação do primeiro código de boas práticas de GC do IBGC - e ainda em evolução na literatura acadêmica nacional.

A Figura 10 detalha as 43 revistas e eventos que publicaram o tema GC em IESs, com predominância da Revista de Administração da Universidade Federal de Santa Maria (UFSM) e dos Colóquios Internacionais sobre Gestão Universitária na América do Sul, tendo publicado 3 $(5,9 \%)$ artigos e $3(5,9 \%)$ trabalhos, respectivamente, dos 51 catalogados. Na sequência, por ordem de volume de publicações, aparecem a Revista Gestão e Planejamento, a Revista Eletrônica de Ciência Administrativa - RECADM, a Revista de Contabilidade do Mestrado em Ciências Contábeis da UERJ (online) e a Revista Alcance (Online), todas com 2 (3,9\%) artigos cada uma, perfazendo um total de $8(15,7 \%)$ artigos, concentrando nesses seis periódicos e eventos $27,5 \%$ de toda a produção sobre GC e IESs, no período analisado.

Segundo Bradford (apud TESTA, 1998; FERREIRA, 2010), um núcleo essencial de revistas forma a base da literatura para todas as disciplinas, e que, portanto, a maioria dos trabalhos importantes é publicada em poucas revistas, sendo considerados assim periódicos de maior fator de impacto. Entretanto, isso não aconteceu no contexto deste estudo, haja vista que os 51 trabalhos e artigos se encontram em 43 periódicos e eventos, um indicativo de que a concentração parece não ser ainda a regra sobre a temática pesquisada. A não concentração dos artigos e trabalhos em determinados periódicos científicos pode estar no fato de que GC em IES é um tema relativamente novo e que começou a despertar maior interesse dos pesquisadores a partir de 2007, conforme pôde ser visualizado na Figura 4. 


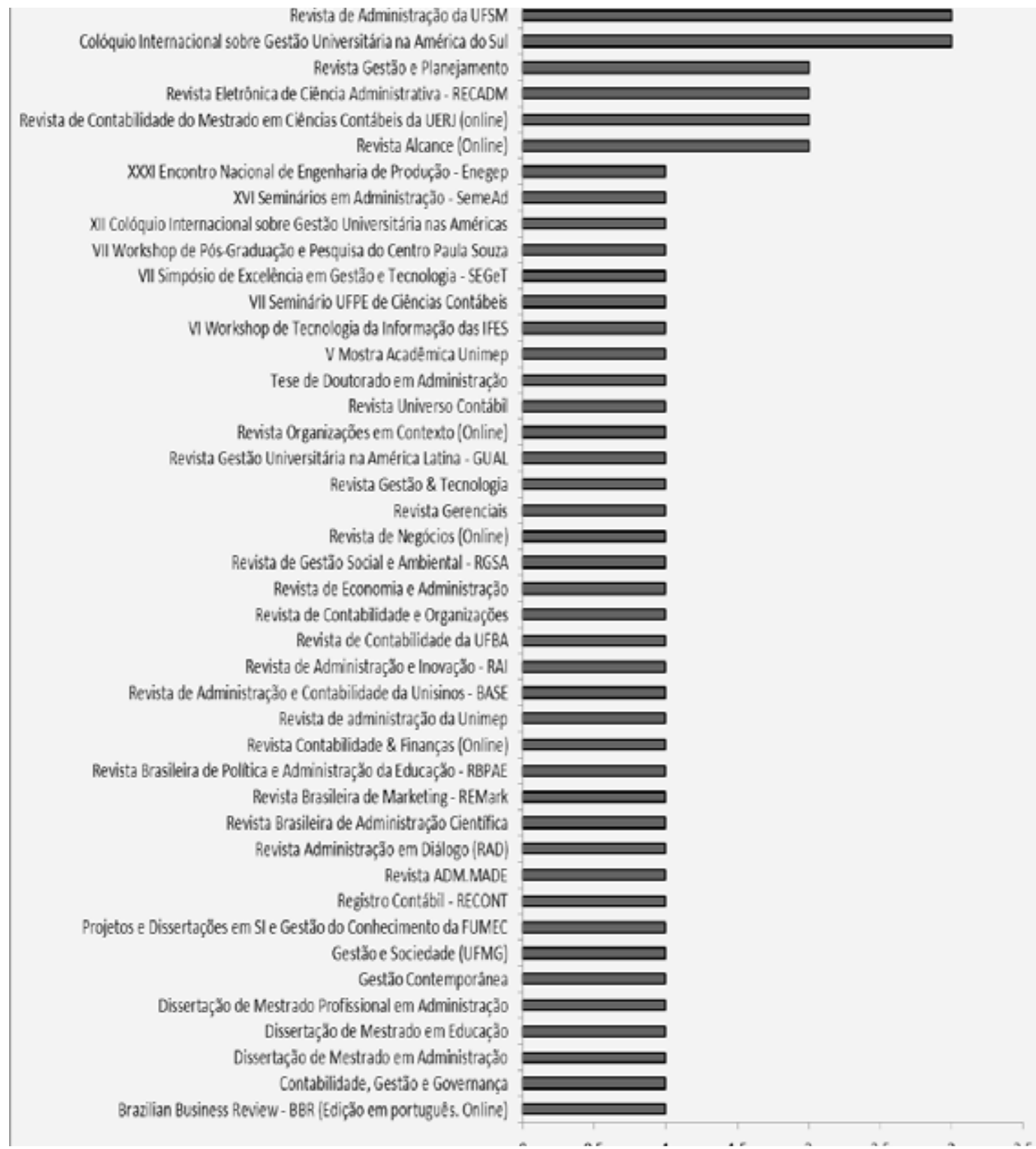

Figura 10 - Número de Artigos por Periódico

Fonte: dados da pesquisa (2013)

Um dos questionamentos do estudo se relaciona aos principais temas em discussão nos artigos e trabalhos sobre GC em IES no período analisado. Assim, os artigos e trabalhos foram classificados em 19 temas, conforme mostra a Figura 11. Nessa etapa, a classificação dos artigos e trabalhos ocorreu baseada na leitura dos títulos, resumos, palavras-chave, referencial teórico, conclusões e, sempre que necessário, houve a leitura dos artigos na íntegra e análise crítica de cada um deles. 


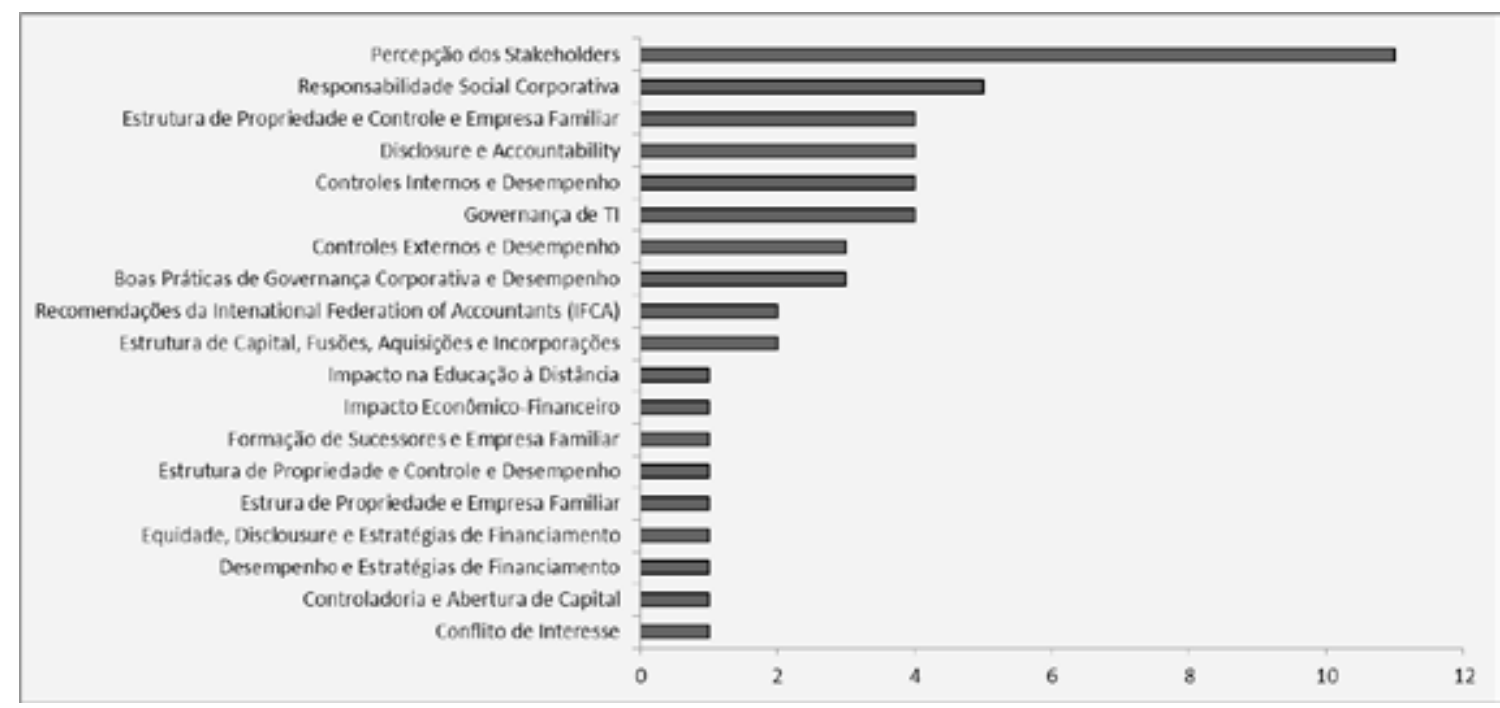

Figura 11 - Número de Artigos por Temas de Base Fonte: dados da pesquisa (2013)

Estudos de governança relacionados à percepção dos stakeholders sobre a qualidade de uma IES, os determinantes da satisfação e os fatores influenciadores da escolha de uma IES são os que tiveram maior destaque, com 11 trabalhos e artigos, o que representa $21,6 \%$ do total de trabalhos e artigos analisados.

O segundo tema com maior incidência foi o relacionado à responsabilidade social corporativa (RSC) das IES, como a preocupação com a inserção do tema no currículo, a conscientização dos agentes internos e externos, a extensão universitária e as práticas adotadas para a gestão ambiental, com 5 artigos nos periódicos e eventos, figurando assim em $9,8 \%$ dos trabalhos publicados.

Os temas estrutura de propriedade e de controle e empresa familiar, disclosure e accountability, controles internos e desempenho e governança de TI aparecem em 4 trabalhos cada um, representando conjuntamente $31,4 \%$ do total de trabalhos e artigos analisados. Os 4 artigos classificados na categoria governança relacionada à estrutura de propriedade e controle e empresa familiar mostraram que nas IES, a dissociação entre a estrutura de propriedade (entidade mantenedora, ou seja, acionistas ou sócios instituidores) e a estrutura de controle (entidade mantida, ou seja, o corpo de dirigentes, o corpo técnico administrativo e o corpo docente) é um imperativo legal. Essa dissociação acaba iniciando os primeiros reflexos do problema de agência, já que os interesses das estruturas de propriedade e de controle podem tornar-se divergentes, ocasionando quebra da relação de confiança e de cooperação. Nesse contexto de divergência, o modelo de stakeholders e o modelo político de GC apresentam-se como mais indicados, com possibilidades de se estabelecerem articulações e relações bastante produtivas, capazes de potencializar o desempenho institucional.

O conceito de transparência (disclosure) vai além do ato de tornar disponíveis as informações impostas pela legislação ou regulamentos. Disclosure resulta em um clima de confiança, tanto internamente quanto nas relações da empresa com terceiros, bem como contempla, além de relatórios financeiros, informações sobre a ação gerencial, a condução e à criação de valor na organização (IBGC, 2010). Já accountability é um termo que se limita aos aspectos financeiros, contábeis e legais que os administradores devem observar ao gerir a organização. É termo que define o conjunto dos meios pelos quais os agentes respondem ao principal (GUIMARÃES, 2008).

Os 4 artigos classificados na categoria disclosure e accountability mostraram que a transparência na gestão escolar mitigou conflitos entre os dirigentes e professores e pode ser considerada 
como uma proxi para boas práticas em GC e desempenho empresarial positivo. Além disso, observouse que a accountability não é praticada em sua integralidade, pois proporciona reduzidas informações contábeis aos stakeholders com demonstrações financeiras ou gerenciais incompletas, nesse quesito. Outro resultado mostrado pelos artigos foi que uma pequena quantidade de IESs disponibiliza suas demonstrações financeiras. Assim, sugere-se que elas também prestem contas publicamente sobre seu desempenho e resultados financeiros, estratégias de gestão e visão de negócios para que estas informações possam ser visualizadas pela sociedade civil de forma transparente.

Os artigos e trabalhos (4 no total) que tratam de controles internos versus desempenho apresentaram uma relação positiva ao mostrar, por exemplo, que um sistema de gestão da qualidade permite à IES gerir mais eficientemente as despesas sociais, orientar os estudantes para melhores oportunidades de emprego e desenvolver um ensino compatível com uma sociedade cada vez mais competitiva e exigente.

A governança de TI busca o compartilhamento das decisões de TI com os demais dirigentes da organização, assim como estabelece as regras, a organização e os processos que nortearão o uso de tecnologia da informação (FERNANDES e ABREU, 2008). Assim, a governança de TI é utilizada para descrever como as pessoas envolvidas em governança de uma organização deverão considerar a TI no seu monitoramento, controle e supervisão.

Os trabalhos e artigos (4 no total) classificados no tema governança de TI evidenciaram o conhecimento acerca dos principais conceitos da governança de $\mathrm{TI}$, mostrando que de forma geral a temática é conhecida. Contudo, a forma como é obtida e aplicada varia muito, pois no geral esse conhecimento quanto à governança de TI foi obtido ora na própria universidade, ora no próprio ambiente de trabalho.

\section{CONSIDERAÇÕES FINAIS}

Este trabalho teve como objetivos identificar e discutir o perfil da produção científica nacional e a evolução do tema GC em IESs nos artigos publicados na biblioteca eletrônica de periódicos científicos (SPELL), no Google Acadêmico e nas revistas nacionais das áreas de Administração, Ciências Contábeis e Turismo classificadas com Qualis entre A2 e B5, no período compreendido entre os anos de 2005 e outubro de 2013, bem como buscou delinear e caracterizar os temas mais discutidos, as abordagens metodológicas que predominam nessa produção, assim como os principais autores da área.

Os resultados mostram que, a despeito dos artigos publicados nos periódicos analisados variarem de um a seis autores, aqueles com dois, três ou quatro autores ocorrem com maior freqüência $(70,7 \%$ do total), podendo ser um indicativo da existência de grupos de pesquisadores ou redes de pesquisa sobre a temática. Esta pesquisa constatou crescimento expressivo da produção no período 2007-2009 (maior do que 29\%) e uma produção média relevante, porém com grande dispersão da quantidade produzida de artigos em torno da média $(\sigma=3,7)$ e também errática no período 2010-2013, com ápice em 2012, e grande queda de produção em 2013, voltando aos níveis observados em 2008. Como a pesquisa foi realizada até o dia 08 de novembro de 2013, é bem provável que a quantidade de trabalhos que foram produzidos até o final daquele ano não tenha revertido esta constatação.

Verificou-se que os 51 trabalhos e artigos foram escritos por 131 autores. Os autores mais prolíficos envolvendo a interface GC em IES no período analisado são Annor da Silva Júnior e Emerson Wagner Mainardes, com 4 publicações, cada um, em eventos e periódicos B1 e B2; Maria José Carvalho de Souza Domingues e Reynaldo Maia Muniz, com 3 publicações também 
em revistas B1 e B2; e Antônio Carlos Giuliani, Eduardo Eugênio Spers, Fábio Vinicius de Macedo Bergamo, Felipe Zambaldi, Mateus Canniatti Ponchio e Priscilla de Oliveira Martins, com 2 publicações, cada um, em eventos e periódicos A2, B1 e B2.

Em relação às abordagens metodológicas preferidas pelos autores, constatou-se que as pesquisas descritivas são predominantes nos estudos de GC em IES analisados. Na comparação, por meio da ANOVA, para verificar a existência de diferença no número de autores em relação ao tipo de pesquisa, foi possível identificar que não há uma diferença estatisticamente significativa entre as médias dos grupos de pesquisas exploratórias, as dos grupos de pesquisas descritivas e as dos de pesquisas exploratório-descritivas, bem como entre as pesquisas descritivas e as exploratório-descritivas em relação ao número de autores. No que tange aos métodos de pesquisa, predomina o qualitativo, que busca mediante estudos de caso (simples e múltiplos), estudos bibliográficos e análises de conteúdo e de discurso, por exemplo, a confirmação de resultados, apesar de alguns dos estudos investigados se utilizarem também da abordagem quantitativa ou híbrida (quali-quantitativa) para otimizar suas análises.

Pôde-se constatar que os 51 artigos e trabalhos da amostra estão dispersos em 43 veículos, sendo apenas aproximadamente $27,5 \%$ deles concentrados em seis periódicos e eventos (5,9\% (03) na Revista de Administração da Universidade Federal de Santa Maria - UFSM, 5,9\% (03) nos Colóquios Internacionais sobre Gestão Universitária na América do Sul, 3,92\% (02) na Revista Gestão e Planejamento, 3,92\% (02) na Revista Eletrônica de Ciência Administrativa - RECADM, 3,92\% (02) na Revista de Contabilidade do Mestrado em Ciências Contábeis da UERJ e $3,92 \%$ (02) na Revista Alcance. Portanto, a maioria dos trabalhos importantes é publicada em diversas revistas e eventos não se observando, ainda, a presença da Lei de Bradford nesta temática, isto é, não há ainda um núcleo essencial de revistas que forma a base da literatura de GC em IESs.

No que se refere aos principais temas discutidos nos artigos, constatou-se a predominância de estudos de governança nas IESs relacionados à percepção dos stakeholders, à responsabilidade social corporativa (RSC), às estruturas de propriedade e de controle e empresa familiar, à disclosure e accountability, aos controles internos e desempenho e à governança de $\mathrm{TI}$, encontrando-se ainda trabalhos classificados em mais de um tema, abordando, por exemplo, ao mesmo tempo controles internos e desempenho e controles externos e desempenho, estrutura de propriedade e de controle e empresa familiar e formação de sucessores e empresa familiar, disclosure e accountability e equidade, disclosure e estratégias de financiamento. Muitos dos temas foram abordados apenas uma única vez, entre eles a interface GC versus impacto na Educação a Distância (EAD), sucessão em IESs familiares, estrutura de propriedade e de controle versus desempenho, conflitos de interesse, configurando-se como lacunas temáticas interessantes para pesquisas futuras.

Como limitação do estudo, ressalta-se que os resultados restringem-se às publicações que se encontram na base de dados do SPELL, do Google Acadêmico e das principais revistas nacionais das áreas de Administração, Ciências Contábeis e Turismo com Qualis entre A2 e B5, deixando de considerar as áreas de Engenharia, Economia e Educação, as quais poderiam acrescentar outras informações ao que foi levantado.

Sugere-se para futuros estudos bibliométricos envolvendo esta temática no Brasil, uma pesquisa ao banco de dados de dissertações de mestrado e teses de doutorado do portal de periódicos da Capes. Outra oportunidade é estender a pesquisa a outros países, com a inclusão de artigos apresentados e publicados nos principais congressos e periódicos internacionais, tanto por autores nacionais quanto por estrangeiros. 


\section{REFERÊNCIAS}

ARAGÃO, L. A. et al.. Visão baseada em recursos e capacidades dinâmicas no contexto brasileiro: a produção e a evolução acadêmica em dez anos de contribuições. Revista Eletrônica de Administração, Porto Alegre, v. 16, n. 2, p. 1-24, 2010.

ARAÚJO, A. M. H. B.; MENDES, P. C. de M.; LUSTOSA, P. R. B.. Governança corporativa no Brasil: contraste de práticas entre instituições financeiras e instituições não financeiras. Revista Universo Contábil, Blumenau, v. 8, n. 2, p. 64-83, abr./jun., 2012.

BABIC, V. Corporate governance problem in transition economies. Winston-Salem: Wake Forest University, Social Science Research Seminar, 2003.

BERLE, A.; MEANS, G. The modern corporation and private property. New York: MacMillan, 1932.

CADBURY COMMITTEE. The report of the committee on the financial aspects of corporate governance. London: Gee and Co. Ltd., Dec. 1992. Disponível em: <www.ecgi.org/codes/ documents/cadbury.pdf>. Acesso em: 03 nov., 2013.

CLAESSENS, S; FAN, P. J.. Corporate governance and investiment policy. Pittsburgh: Center of Research on Contracts and the Structure of Enterprise. Working paper, 1996.

CERVO, A. L.; BERVIAN, P. A.. Metodologia científica. 4. ed. São Paulo: Makron Books, 1996.

COOPER, H. M.; LINDSAY, J. J. Research synthesis and meta-analysis. In: L. Bickman; D. J. Rog; Handbook of applied social research methods. Thousand Oaks, CA: Sage Publications, 1998.

CRESWELL, J. W.. Projeto de pesquisa: métodos qualitativo, quantitativo e misto. 2. ed. Porto Alegre: Artmed, 2007. 248 p.

DUARTE, R. S.; KHALIL, R. O.; QUELHAS, O.. Governança: uma ferramenta desconhecida pelas instituições de ensino? SEGeT - Simpósio de Excelência em Gestão e Tecnologia, 2008.

FERNANDES, A. A.; ABREU, V. F.. Implantando a governança de TI: da estratégia a gestão dos processos e serviços. 2 ed., Rio de Janeiro: Brasport, 2008.

FERREIRA, Ana Gabriela Clipes. Bibliometria na avaliação de periódicos científicos. Revista de Ciência da Informação, v. 11, n. 3, jun./2010.

FIELD, Andy. Descobrindo a estatística usando o SPSS. Tradução Lorí Viali. 2 ed.. Porto Alegre: Artmed, 2009.

FONTES FILHO, J. R.; PICOLIN, L. M.. Governança corporativa em empresas estatais: avanços, propostas e limitações. Revista de Administração Pública, Rio de Janeiro, v. 42, n. 6, p. 1163-88, nov./dez., 2008.

GALVÃO, H. M.; CORRÊA, H. L.; ALVES, J. L.. Modelo de avaliação de desempenho global para instituição de ensino superior. Revista de Administração da UFSM, Santa Maria, v. 4, n. 3, p. 425441, set./dez., 2011.

GIL, A. C.. Como elaborar projetos de pesquisa. 4. ed. São Paulo: Atlas, 2002. 
GOOGLE ACADÊMICO. 2013. Sobre o Google Acadêmico. Disponível em: <http://scholar.google. com.br/intl/pt-BR/scholar/about.html>. Acesso em: 12 nov., 2013.

GUIMARÃES, L. S. R.. Governança no terceiro setor: estudo descritivo-exploratório do comportamento de conselhos curadores de fundações empresariais no Brasil. Tese (Doutorado em Administração) - Faculdade de Economia, Administração e Contabilidade, Universidade de São Paulo, São Paulo, 2008.

INSTITUTO BRASILEIRO DE GOVERNANÇA CORPORATIVA (IBGC). Código das melhores práticas de governança corporativa. 4.ed. São Paulo: IBGC, 2010.

LEITE, F. T.. Metodologia científica: iniciação à pesquisa científica, métodos e técnicas de pesquisa, metodologia da pesquisa e do trabalho científico (monografias, dissertações, teses e livros). Fortaleza: Universidade de Fortaleza, 2004.

LEITE FILHO, G. A. Padrões de produtividade de autores em periódicos de congressos na área de contabilidade no Brasil: um estudo bibliométrico. In: Congresso USP Controladoria e Contabilidade. Anais Eletrônicos... Congresso USP de Controladoria e Contabilidade, 2006. Disponível em: <http://www.congressousp.fipecafi.org>. Acesso em: 30 ago. 2013.

MAINARDES, E. W.; DESCHAMPS, M.; TONTINI, G.. Percepções dos stakeholders sobre a qualidade de uma instituição de ensino superior. Revista Eletrônica de Ciência Administrativa, v. 8, n. 1, p. 90-105, mai., 2009.

MALHOTRA, Naresh. Pesquisa de marketing: uma orientação aplicada. 6 ed.. Porto Alegre: Bookman, 2012.

MATIAS-PEREIRA, J.. A governança corporativa aplicada no setor público brasileiro. Administração Pública e Gestão Social, Viçosa, v. 2, n. 1, p. 109-134, jan./mar., 2010.

MONKS, R. A. G.; MINOW, N.. Corporate governance. 3. ed. Oxford: Black-well, 2004.

MURITIBA, S. N. et al.. 2010. Governança corporativa no Brasil: uma análise bibliométrica das publicações dos últimos doze anos. In: Seminários em Administração, 13, São Paulo, 2010. (Semead). Anais Eletrônicos... São Paulo, Semead, p. 1-17. Disponível em: <http://www.ead.fea. usp.br/semead/13semead/resultado/trabalhosPDF/887.pdf>. Acesso em: 27 ago., 2013.

NOGUEIRA, M. da G. S.; GARCIA, T. E. M.; RAMOS, M. da G. G.. Governança corporativa, responsabilidade social corporativa: a visão de atores de uma instituição de ensino superior - IES federal. Revista Gestão Universitária na América Latina, Florianópolis, v. 5, n. 3, p. 222-244, dez., 2012.

ORGANIZATION FOR ECONOMIC CO-OPERATION AND DEVELOPMENT (OECD ou OCDE). OECD Principles of corporate governance, 2004. Disponível em: <www.oecd.org/ dataoecd/32/18/31557724.pdf>. Acesso em: 03 nov., 2013.

POLO, A.. Corporate Governance of Banks: the current state of the debate. Jan., 2007. Disponível em: <http://mpra.ub.uni-muenchen.de/2325/>. Acesso em: 03 nov., 2013. http://dx.doi. org/10.2139/ssrn.958796.

ROSSETTI, J. P.; ANDRADE, A.. Governança corporativa: fundamentos, desenvolvimento e tendências. 6. ed. São Paulo: Atlas, 2012. 
SANTOS, A. P.. Governança corporativa e desempenho em instituições privadas de ensino superior: um estudo de caso em minas gerais. Revista Contabilidade da UFBA, Salvador-Ba, v. 2, n. 3, p. 79-94, set./dez., 2008.

SERRA, F. A. R. et al.. Evolução da pesquisa em RBV: um estudo dos últimos enanpad's. Revista Brasileira Estratégia, Curitiba, v. 1, n. 1, p. 39-56, 2008.

SHLEIFER, A.; VISHNY, R. W. A survey of corporate governance. Journal of Finance, v. 52, p. 737783, 1997.

SILVA JÚNIOR, A.; MUNIZ, R. M.; MARTINS, P. de O.. Governança corporativa na IES familiar de grande porte: um estudo de caso. Revista Alcance Eletrônica, v. 16, n. 3, p. 286-303, set/dez., 2009.

SILVEIRA, A. M. Governança corporativa no Brasil e no mundo: teoria e prática. Rio de Janeiro: Elsevier, 2010.

SCIENTIFIC PERIODICALS ELECTRONIC LIBRARY (SPELL). 2013. Estatísticas do Spell. Disponível em: <http://www.spell.org.br/>. Acesso em: 08 nov., 2013.

SUBRAMANYAM, K. Bibliometric studies of research collaboration: a review. Journal of Information Science, USA, v. 6, n. 1, p. 33, CILIP, 1983.

TESTA, J. A base de dados ISI e seu processo de seleção de revistas. Ciência da Informação, Brasília, v. 27, n. 2, p. 233-235, 1998.

WALTER, S. A. et al.. Visão baseada em recursos: uma análise dos delineamentos metodológicos e da maturidade dessa abordagem na área de estratégia do enanpad 1997-2007. In: XXXII Encontro da Associação Nacional de Pós-Graduação e Pesquisa em Administração (EnANPAD. Anais Eletrônicos... Rio de Janeiro: ANPAD, 2008. Disponível em: <http://www.anpad.org.br/>. Acesso em: 30 ago., 2013.

WILLIAMSON, O. The mechanisms of governance. Oxford: Oxford University Press, 1996. 